\section{Plasma exchange in non-haemophiliac patients with inhibitors to factor VIIIC}

Treatment of patients with inhibitors to factor VIII clotting activity (VIIIC) remains an unsolved clinical problem. Recent reports ${ }^{12}$ suggest that plasma exchange (or plasmapheresis) contributes to the management of haemophiliacs with inhibitors. This report describes how plasmapheresis helped achieve control in two non-haemophiliac patients with acquired inhibitors to factor VIIIC.

\section{Case reports}

Case 1-A 72-year-old man suddenly developed spontaneous bruising, a large ileopsoas haematoma, and femoral nerve palsy. Investigations revealed a prolonged kaolin cephalin clotting time (KCCT) of 93 seconds (control $37 \mathrm{~s}$ ), a plasma factor VIIIC concentration of $0.02 \mathrm{U} / \mathrm{ml}$, and the presence of an inhibitor to factor VIII at a concentration of $13 \mathrm{U} / \mathrm{ml}$. This "in-house" inhibitor titre was calculated by adding standardised human factor VIII concentrate to plasma until neutralisation occurred, the neutralisation point being that concentration of factor VIII concentrate which clotted the patient's plasma in the same time as an inhibitor-free control plasma. ${ }^{3}$ Initial treatment with human factor VIII concentrates produced little clinical benefit and minimal rise in factor VIIIC. Porcine factor VIIIC (Hyate C: Speywood Laboratories) produced an excellent rise in factor VIIIC. Its further use was precluded, however, by a severe anaphylactic reaction with bronchospasm, pulmonary crepitations, and peripheral circulatory collapse which required extensive resuscitative measures. After 10 days' factor VIII replacement treatment, without clinical improvement and with continuing spontaneous bruising, the inhibitor concentration had risen to over $50 \mathrm{U} / \mathrm{ml}$ with the KCCT at $178 \mathrm{~s}$ (control $40 \mathrm{~s}$ ). Intensive plasmapheresis was started to reduce the quantity of circulating antibody; this was combined with immunosuppressive treatment (azathioprine and prednisolone) to inhibit antibody production. Eight 3-litre plasma exchanges over 10 days using an IBM 2997 cell separator and replacement with equal quantities of fresh frozen plasma and human albumin fraction $43 \mathrm{~g}$ /litre (Immuno Ltd) produced rapid clinical improvement in the femoral nerve palsy. No further fresh bleeding developed. Laboratory tests reflected this improvement, the KCCT shortening to $68 \mathrm{~s}$ (control $38 \mathrm{~s}$ ), the plasma factor VIIIC concentration rising to $0.05 \mathrm{U} / \mathrm{ml}$, and inhibitor concentration falling to $8 \mathrm{U} / \mathrm{ml}$. Immunosuppressive treatment was gradually reduced. Two months later the inhibitor titre was $1 \mathrm{U} / \mathrm{ml}$ with a factor VIIIC assay of $0.34 \mathrm{U} / \mathrm{ml}$.

Case 2-A 28-year-old woman underwent an apparently uneventful caesarean section for fetal distress, but within one week she developed a large wound haematoma. Surgical exploration showed no bleeding vessels, but profuse bleeding continued with the development of a massive anterior abdominal wall haematoma. Transfusion of 14 units of blood was required before the patient was fit to be transferred. Investigation showed an inhibitor to factor VIIIC of $2.5 \mathrm{U} / \mathrm{ml}$, a KCCT of $75 \mathrm{~s}$ (control $37 \mathrm{~s}$ ), and plasma factor VIIIC concentration of $0.04 \mathrm{U} / \mathrm{ml}$. Immunosuppressive drugs were withheld because of the risk of wound dehiscence. Infusions of high doses of human factor VIII concentrates raised the plasma concentration of factor VIIIC but produced no clinical improvement and were associated with a rise in the inhibitor concentration to over $50 \mathrm{U} / \mathrm{ml}$. After two weeks intrarenal and retroperitoneal bleeding had produced a potentially fatal clinical deterioration. Intensive plasmapheresis and immunosuppressive treatment with azathioprine and prednisolone were therefore started. Two plasma exchanges of 1.5 litres and four of 3.0 litres, using human albumin fraction (Immuno Ltd) as the only replacement fluid, were performed during eight days. This resulted in pronounced clinical improvement with no further fresh bleeding. Laboratory tests now showed a KCCT of $53 \mathrm{~s}$ (control $40 \mathrm{~s}$ ), plasma factor VIIIC concentration of $0.23 \mathrm{U} / \mathrm{ml}$, and inhibitor concentration of $1 \mathrm{U} / \mathrm{ml}$. Two months later, with immunosuppressive drugs withdrawn, coagulation results were virtually identical, the abdominal haematoma almost resolved, and the abdominal scar soundly healed.

\section{Comment}

Although about $75 \%$ of non-haemophiliac patients with inhibitors respond to immunosuppressive drugs, the response is often slow and variable. ${ }^{4}$ Treatment is difficult to assess, but reports have shown the value of plasmapheresis in haemophiliacs with inhibitors. ${ }^{12}$ Plasmapheresis appears rapidly effective and has advantages over other treatments. Circulating antibody concentrations are rapidly lowered, and the risk of hepatitis from albumin products is negligible. Anamnestic reactions associated with factor VIII concentrates are avoided or minimal if fresh frozen plasma is given as replacement fluid. "Activated" prothrombin complexes have been advocated" but are expensive and potentially thrombogenic.

These two cases indicate that extensive plasmapheresis with immunosuppression should be considered early in the treatment of non-haemophiliacs with inhibitors. Plasmapheresis to remove circulating factor VIII inhibitor antibody may in such cases be a lifesaving measure.

We thank Dr Pauline Bailley of Dumfries and Galloway Royal Infirmary and Dr David Ellis of Inverclyde Royal Infirmary for referring the patients.

${ }^{1}$ Wensley RT, Stevens RF, Burn AM, Delamore IW. Plasma exchange and human factor VIII concentrate in managing haemophilia A with factor VIII inhibitors. $\mathrm{Br} \mathrm{Med} 7 \mathrm{f} 1980 ; 281: 1388-9$.

2 Colcroft R, Tamagrim G, Dormandy KM. Serial plasmapheresis in a haemophiliac with antibodies to Factor VIII. $\mathcal{f}$ Clin Pathol 1977;30: 763-5.

3 Tse D, Fekete L, Shanbrom E. A simple procedure for accurate quantitation of Factor VIII inhibitors. Thrombosis et Diathesis Haemorrhagica (Stuttgart) $1970 ; 23: 19-25$.

1 Shapiro SS, Hultin M. Acquired inhibitors to the blood coagulation factors. Semin Thromb Hemostas 1975;1:336-85.

5 Kurczynski EM, Penner JA. Activated prothrombin concentrate for patients with factor VIII inhibitors. N Engl f Med 1974 ;291 :164-7.

(Accepted 17 June 1981)

\section{Glasgow Royal Infirmary, Glasgow G4 OSF}

J G ERSKINE, MRCP, MRCPATH, senior registrar in haematology (present appointment: consultant haematologist, Ballochmyle Hospital, Mauchline, Ayrshire)

A K BURNETT, MRCP, MRCPATH, consultant haematologist

I D WALKER, MB, MRCPATH, consultant haematologist

J F DAVIDSCN, FRCP(ED), MRCPATH, consultant haematologist

\section{Diagnosis of bladder neck incompetence without use of capital equipment}

In cases where symptoms suggest genuine stress urinary incontinence but where stress leakage cannot be shown during examination, alternative diagnostic information is sought. Failure of the primary mechanism of continence at the bladder neck must precede any stress leakage and there is a small range of urethral measurements and tests aimed at identifying failure, or likely failure of this mechanism. These fall into two groups: those which infer that the bladder neck is likely to open during stress, such as the urethral pressure profile test and coughing pressure transmission tests ${ }^{1}$; and those in which actual penetration of fluid into the urethra can be seen or detected, such as cineradiography ${ }^{2}$ and the fluid-bridge test. ${ }^{3}$

We describe a development of the fluid bridge test which provides clear and useful information on urethral incompetence without the use of capital equipment.

\section{Method}

The new test, which we call the fluid bridge (flow) test, requires only a simple plastic catheter, preferably with calibration marks added. To perform the test the catheter is passed until the eye is in the bladder and urine flows freely through it (fig $(a)$ ). It is then eased out very slowly until the flow of urine ceases, thus locating the bladder neck (fig $(b)$ ). Next it is moved a chosen distance (usually $0.5 \mathrm{~cm}$ ) down the urethra-calibration marks are helpful at this point (fig $(c)$ ). The patient is asked to cough. If the cough causes urine to flow through the catheter (fig $(d)$ ) then the bladder neck is shown to open to the chosen point, and the test is said to be positive. If no drops emerge the test is negative. If the test is positive it can be repeated at distal points to see how far the urethra opens during cough.

While the patient is coughing the catheter needs to be kept in position. This can be achieved with a sticking plaster applied to the medial aspect of the thigh, but we use a special clip ${ }^{4}$ set in a rubber ring pessary held between the patient's thighs, which saves time. If there is doubt as to the position of 
the catheter, however, it can be relocated at any time by repeating the procedure described above.

The figure shows a side-opening catheter, but the results we obtained with a catheter having a single hole at the tip appear to be the same.

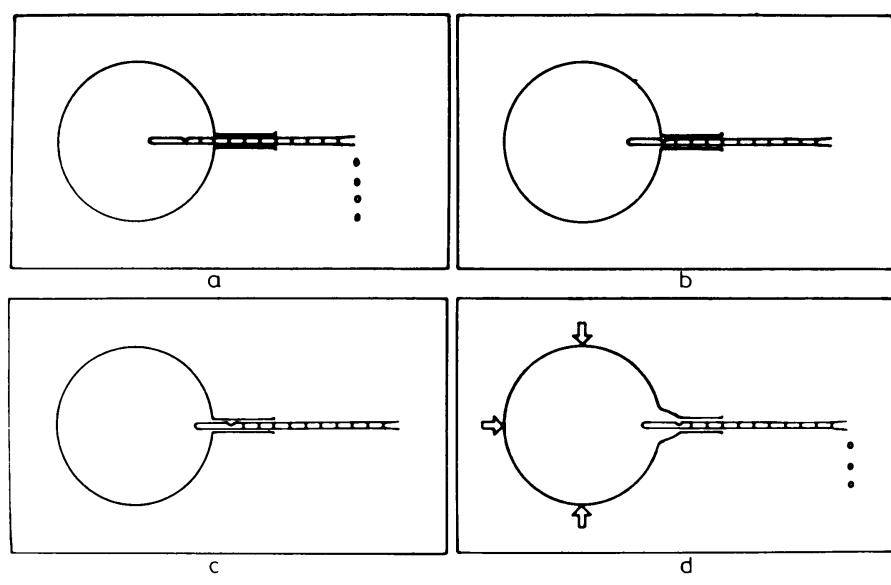

Four stages of fluid bridge (flow) test: (a) catheter is passed up into bladder, $(b)$ bladder neck is located, (c) test position is selected, $(d)$ bladder neck opens during cough.

\section{Comment}

We used this method on more than 50 patients and found the results indistinguishable from those of the fluid bridge (pressure) test. The test is reproducible, though the distance from the bladder neck at which the result is positive may vary slightly with the strength of the cough.

The importance of the fluid bridge test has already been established and it appears to be a more sensitive indicator of bladder neck incompetence than other urodynamic tests, with the possible exception of pressure-cine-cystography. ${ }^{4}$ This simpler test permits wider use of work already done with more complex apparatus. Because no apparatus is required it should be possible to conduct this test in the outpatient clinic, avoiding referral of some patients to specialised units, saving time and effort.

1 Asmussen M, Ulmsten U. Simultaneous urethro-cystometry with a new technique. Scand $\mathcal{F}$ Urol Nephrol 1976;10:7-11.

${ }^{2}$ Bates CP, Whiteside CG, Turner Warwick R. Synchronous cine/pressure/ flow/cystourethrography with special reference to stress and urge incontinence. $\mathrm{Br} \mathcal{F}$ Urol 1970;42:714-23.

${ }^{3}$ Brown M, Sutherst J. A test for bladder neck competence: the fluid bridge test. Urol Int $1979 ; 34: 403-9$.

' Sutherst JR, Brown M. Detection of urethral incompetence. Erect studies using the fluid bridge test. $\mathrm{Br} \mathcal{F}$ Urol (in press).

${ }^{5}$ Sutherst JR, Brown M. Detection of urethral incompetence in women using the fluid bridge test. Br $\mathcal{F}$ Urol 1980;52:138-42.

(Accepted 17 fune 1981)

Royal Liverpool Hospital, Liverpool L7 8XP

M SHAWER, MB, MRCOG, research registrar (now registrar, Kilton Hospital, Worksop)

M BROWN, BSC, PHD, medical physicist

J SUTHERST, MD, FRCOG, senior lecturer in obstetrics and gynaecology

\section{No evidence of transfer of fluoride from plasma to breast milk}

Artificially fluoridated drinking water is supplied throughout the world as a mass-prophylactic agent against dental caries. No data are available, however, on the transfer of fluoride from maternal plasma to breast milk. We have therefore compared the fluoride concentrations in the plasma and breast milk of nursing mothers after an oral dose of fluoride.

\section{Subjects, methods, and results}

Five mothers aged 27-36 years were given fluoride by mouth on the third postpartum day. A dose of $1.5 \mathrm{mg}$ was given as an aqueous solution of sodium fluoride in the morning after fasting for 10 hours. Blood and breast milk were sampled simultaneously in a non-glass system before and 30 , 60,90 , and 120 minutes after the dose. Fluoride concentration in plasma was measured with a fluoride-sensitive electrode, ${ }^{1}$ and in milk was determined using a modified microdiffusion technique. ${ }^{2}$ Recovery experiments showed no evidence that fluoride binds to the constituents of breast milk. Hence the figures given for breast milk represent exclusively free fluoride.

The plasma fluoride concentration in all subjects rapidly increased after fluoride intake (figure). The highest plasma concentrations appeared 30 minutes after dosing, when they varied between 3.6 and $4.5 \mu \mathrm{mol} / \mathrm{l}$ (70 and $86 \mathrm{ng} / \mathrm{ml}$ ). This rapid absorption was in line with our results from oral single-dose studies in man. ${ }^{3}$ There was no corresponding increase in the fluoride concentrations in the breast milk, the values varying between 0.1 and $0.4 \mu \mathrm{mol} / 1$ ( 2 and $8 \mathrm{ng} / \mathrm{ml}$ ).

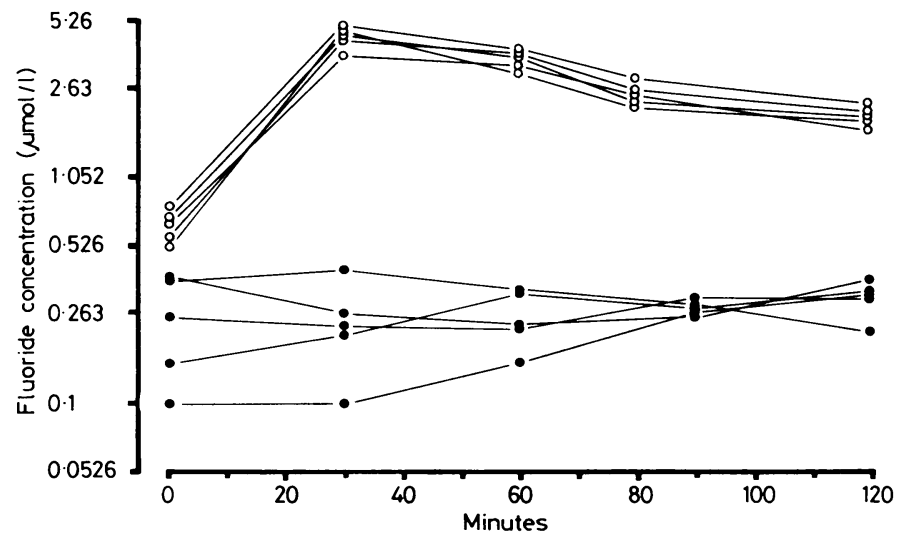

Plasma (open symbols) and breast milk (closed symbols; fluoride concentrations in five mothers after oral dose of $1.5 \mathrm{mg}$ fluoride as sodium fluoride solution.

Conversion: SI to traditional units-Fluoride: $1 \mu \mathrm{mol} / 1 \approx 19 \mathrm{ng} / \mathrm{ml}$.

\section{Comment}

These findings show that plasma fluoride is poorly transferred to breast milk and infants thus receive almost no fluoride during breast feeding. This is in contrast to another halogen, bromide, which reportedly accumulates in breast milk. ${ }^{4}$

In this study plasma and milk were sampled for a period of two hours after a single dose had been taken by the mother. The possibility of delayed transfer, not detected during the period of observation, was ruled out by other results from our laboratory, which showed that fluoride concentrations in breast milk remain steady, even when fluoride is given repeatedly and despite considerable variations in the maternal plasma fluoride concentrations.

The reason for the poor transfer of fluoride into the cells of the breast is obscure. Such a phenomenon has not been observed in other mammalian glands-for example, the salivary glands. The concentration in saliva follows that in plasma, and the, ratio between salivary and plasma fluoride is around $0.65 .^{3}$ Fluoride is excluded from certain cultured cells, ${ }^{5}$ but whether the same mechanisms are concerned in the mammary gland remains to be clarified.

Infants fed on milk substitutes receive higher fluoride doses, especially in areas where the drinking water is rich in fluoride. Thus in an area where the fluoride concentration is one part per million the daily fluoride dose in the newborn infant will be about 800 $1000 \mu \mathrm{g}$ when a milk substitute is used, whereas the fluoride dose for breast-fed children in the same area will not exceed $10 \mu \mathrm{g} / \mathrm{day}$. The existence of a physiological plasma-milk barrier against fluoride suggests that the newborn is actively protected from this halogen. Hence the recommendation made in several countries to give breastfed infants fluoride supplementation should be reconsidered.

This study was supported by grants from the Swedish Medical Research Council (project Nos 6002 and 522) and the Swedish Patent Revenue Research Fund.

${ }^{1}$ Ekstrand J. A micromethod for determination of fluoride in blood plasma and saliva. Californian Tissue Research 1977;23:225-8. 